\title{
MÓI LIÊN QUAN VỀ HÌNH ẢNH CộNG HƯỞNG TỪ VÀ LÂM SÀNG SAU PHẪU THUẠT RÁCH CHÓP XOAY
}

\author{
Đoàn Thị Giang ${ }^{1,2}$, Đinh Trung Thành² và Phạm Hồng Đức $\mathbf{c}^{1,2,}, \mathbb{U}$ \\ ${ }^{1}$ Trường Đại học Y Hà Nội \\ ${ }^{2} B$ ệnh viện Đa khoa Saint Paul Hà Nội
}

\begin{abstract}
Mục đích của nghiên cứu này là xác định mối liên quan giữa hình ảnh MRI sau phẫu thuật và lâm sàng trên 52 bệnh nhân sau phẫu thuật nội soi chóp xoay it nhất 6 tháng, thời gian từ tháng 01/2020 đến tháng 06/2021. Kết quả cho thấy tỷ lệ rách tái phát gân trên gai sau phẫu thuật là 9,62\%; các bệnh nhân đều đã được phát hiện rách tái phát trong thời gian trước 6 tháng. Lâm sàng sau phẫu thuật cải thiện đáng kể đa số ở mức tốt và rất tốt. Có sự phù hợp giữa phân độ Sugaya trên hình ảnh MRI với điểm lâm sàng dựa theo UCLA, ASES với $p<0,001$. Mối liên quan giữa thoái hóa mỡ cơ và teo cơ với điểm lâm sàng và với tỷ lệ rách tái phát có ý nghĩa với $p<0,05$. Như vậy, các bệnh nhân có phân độ Sugaya thấp hơn thì tình trạng khớp vai sau phẫu thuật tốt hơn. Các bệnh nhân có chỉ số thoái hóa mỡ cao và teo cơ trên MRI có tình trạng khớp vai kém hơn và có nguy cơ rách tái phát cao hơn.
\end{abstract}

Từ khóa: Sau phẫu thuật rách chóp xoay, rách tái phát, MRI sau phẫu thuật, Sugaya, UCLA, ASES.

\section{I. ĐẠT VẤN ĐÊ}

Chóp xoay là cấu trúc đóng vai trò quan trọng trong việc vận động phức tạp của khớp vai. Thương tổn chóp xoay là bệnh lý hay gặp nhất trong nhóm bệnh lý khớp vai, ${ }^{1}$ sau phẫu thuật, khoảng $25 \%$ số bệnh nhân xuất hiện đau hoặc hạn chế vận động. ${ }^{2}$ Tỷ lệ rách tái phát được báo cáo trong y văn dao động từ $9 \%$ đến $36 \%$. $^{3-5}$ Chụp cộng hưởng từ (MRI) của khớp vai sau phẫu thuật được thực hiện thời điểm ít nhất 6 tháng sau phẫu thuật. Khoảng thời gian này được lựa chọn dựa trên các nghiên cứu trước đây cho thấy đây là khoảng thời gian đủ để đánh giá khả năng chữa lành gân. ${ }^{6,7}$ Năm 2014, Choi và cộng sự thực hiện nghiên cứu trên 147 bệnh nhân về các yếu tố

Tác giả liên hệ: Phạm Hồng Đức,

Trường Đại học Y Hà Nội

Email: phamhongduc@hmu.edu.vn

Ngày nhận: 04/08/2021

Ngày được chấp nhận: 29/08/2021 ảnh hưởng đến tình trạng lâm sàng sau phẫu thuật chóp xoay ít nhất 12 tháng cho thấy tỷ lệ rách tái phát là $17 \%$, rách tái phát được tìm thấy ở 18 (35,3\%) trong số 51 trường hợp thoái hóa mỡ độ 3 và độ $4 .{ }^{4}$ Năm 2016, nghiên cứu của Malavolta và cộng sự theo dõi dọc tại các thời điển 3 tháng, 6 tháng, 12 tháng sau phẫu thuật chóp xoay trên 54 bệnh nhân cho thấy tất cả bệnh nhân rách tái phát đều gặp trong 6 tháng đầu tiên, bệnh nhân có độ Sugaya trên MRI cao hơn thì điểm UCLA thấp hơn. ${ }^{8}$ Tại Việt Nam, năm 2018, Phan Đình Mừng và cộng sự nghiên cứu tương quan giữa chỉ số thoái hóa mỡ cơ trên gai trên MRI với phục hồi chức năng khớp vai sau phẫu thuật, kết quả cho thấy tỷ lệ rách tái phát là $13,5 \%$, chỉ số thoái hóa mõ̃ của nhóm liền gân cao hơn nhóm rách tái phát.9 Tuy nhiên chưa có nghiên cứu đánh giá cụ thể theo phân độ Sugaya và ảnh hưởng của teo cơ trên MRI đến với chức năng vai sau phẫu thuật. Mục đích của nghiên cứu này xác định mối liên 
quan hình ảnh MRI với biểu hiện lâm sàng sau phẫu thuật rách chóp xoay.

\section{II. ĐỐI TƯỢNG VÀ PHƯƠNG PHÁP}

\section{1. Đối tượng}

Nghiên cứu gồm 52 bệnh nhân (BN) tái khám sau phẫu thuật nội soi khâu chóp xoay ít nhất 6 tháng còn các triệu chứng đau hoặc hạn chế vận động khớp vai tại Bệnh viện Xanh Pôn và Bệnh viện Đại học $Y$ Hà Nội từ tháng 01/2020 đến tháng 06/2021, loại trừ các bệnh nhân được ghép gân và không tuân thủ qui trình phục hồi chức năng sau mổ.

\section{Phương pháp}

Cách thức chụp tạo ảnh CHT và phân tích hình ảnh: Sử dụng máy MRI Siemens 1.5 Tesla và 3 Tesla. Qui trình kỹ thuật chụp sử dụng trong nghiên cứu bao gồm chuỗi xung PD (proton density) fatsat (xoá mỡ) theo 3 mặt phẳng ngang, đứng dọc, và đứng ngang; chuỗi xung $\mathrm{T} 1 \mathrm{~W}$ theo hai mặt phẳng đứng ngang và đứng dọc.

Hình ảnh MRI được phân tích bởi hai bác sĩ chẩn đoán hình ảnh có kinh nghiệm, đã được thông báo rằng các bệnh nhân có tiền sử phẫu thuật chóp xoay nhưng không biết về kích thước và vị trí gân rách trước phẫu thuật.

Các biến số đánh giá hình ảnh MRI bao gồm: Độ dày gân, tín hiệu gân, phân theo các chỉ số: tình trạng gân theo phân loại của Sugaya phân chia thành 5 độ, với độ IV, V tương đương với sự rách tái phát gân cơ trên gai sau phẫu thuật. Độ I: Gân dày đều, tín hiệu giảm đồng nhất trên T2/PD-FS; Độ II: Gân dày đều, tăng tín hiệu một phần trong gân; Độ III: Gân dày mỏng không đều, không có đường mất liên tục; Độ IV: Đường mất liên tục nhỏ trên > 1 lát cắt, gợi ý vết rách nhỏ; Độ V: Đường mất liên tục lớn, trên tất cả lát cắt gợi ý vết rách trung bình hoặc lớn.

Ngoài ra trên hình ảnh MRI đánh giá chỉ số teo cơ trên gai trên mặt phẳng đứng dọc qua gốc của mỏm quạ, kẻ một đường thẳng nối mỏm quạ và gai vai, phân chia thành 4 độ: độ 0 (không teo cơ): bờ cơ lồi qua đường thẳng, độ 1 (teo nhẹ cơ): bờ cơ tiếp xúc với đường thẳng, độ 2 (teo cơ trung bình): bờ cơ lõm dưới đường thẳng, độ 3 (teo cơ nặng): hầu như không quan sát thấy cơ. Chỉ số thoái hóa mỡ chia thành 5 độ: Độ 0 : cơ bình thường; Độ 1: có một vài dải mỡ trong cơ; Độ 2: mõ chiếm < 50\% cơ; Độ 3: mỡ chiếm 50\% cơ; Độ 4: mõ chiếm > 50\% cơ.

Phân tích đặc điểm lâm sàng: Tình trạng lâm sàng sau mổ được đánh giá bởi bác sỹ chuyên khoa phẫu thuật cơ xương khớp có kinh nghiệm về bệnh lý khớp vai, không biết trước về kết quả MRI.

Thang điểm lâm sàng: tính theo thang điểm ASES (gồm 2 bộ câu hỏi về điểm đau và chức năng khớp vai trong hoạt động thường ngày) và thang điểm UCLA (gồm 5 bộ câu hỏi về đau, chức năng, tầm vận động, sức cơ gấp ra trước và độ hài lòng của $B N$ ), phân chia điểm UCLA thành 4 mức độ: rất tốt (34 - 35 điểm); tốt (28 33 điểm); trung bình (21 - 32 điểm), và xấu (< 21 điểm).

\section{Xử lý số liệu}

Thống kê mô tả, bao gồm trung bình, độ lệch chuẩn, tỷ lê phần trăm sử dụng cho các biến ngẫu nhiên, biến định lượng. Khi so sánh hai biến định tính sử dụng kiểm định Khi bình phương và Fisher's Exact (sử dụng khi tần số mong đợi của mỗi ô < 5). Khi so sánh các trung bình ở nhiều nhóm độc lập sử dụng kiểm định One-way ANOVA. Tất cả các số liệu thống kê được phân tích bằng phần mềm SPSS 20.0.

\section{4. Đạo đức nghiên cứu}

Đây là một phần của đề tài tốt nghiệp bác sỹ nội trú và đã được thông qua hội đồng đề cương của Trường Đại học $Y$ Hà Nội. Tất cả các qui trình kỹ thuật được thực hiện theo Dữ liệu thông tin là nghiên cứu mô tả không can 
thiệp, nên không ảnh hưởng đến quyền và nghĩa vụ của bệnh nhân tham gia nghiên cứu.

\section{KÉT QUẢ}

Nghiên cứu gồm có 52 bệnh nhân (BN), 23 nam và 29 nữ (tỷ lệ $1 / 1,3$ ). Tuổi trung bình là $60,27 \pm 8,41$ (36 - 76); trong đó 38 trường hợp được phẫu thuật chóp xoay bên phải, 14 BN phẫu thuật bên trái (tỷ lệ phải/trái là 2,7). Tỷ lệ rách tái phát sau phẫu thuật là $5 / 52(9,62 \%)$, các bệnh nhân này đều đã được phát hiện rách tái phát trong thời gian trước 6 tháng, không có bệnh nhân nào phát hiện rách tái phát trong thời gian sau 6 tháng

Kết quả cho thấy điểm ASES tăng từ 28,76 $\pm 15,07$ trong giai đoạn trước phẫu thuật lên $95,83 \pm 4,89$ sau phẫu thuật trên 6 tháng. Sau phẫu thuật, mức độ đánh giá lâm sàng theo UCLA chủ yếu nằm ở mức tốt $(61,54 \%)$ và rất tốt $(36,54 \%)$, chỉ có 01 bệnh nhân ở mức trung bình (1,92\%), không có bệnh nhân nào ở mức xấu.

Giữa hai nhóm liền gân và rách tái phát sau phẫu thuật có sự khác biệt về thang điểm lâm sàng tính theo thang điểm UCLA $(p=0,003<$ $0,01)$ và ASES $(p<0,001)$. Khi xét riêng điểm UCLA và ASES sau phẫu thuật theo phân độ Sugaya thì sự khác biệt về điểm lâm sàng giữa các nhóm có ý nghĩa thống kê với $p<0,001$. (Bảng 1)

Bảng 1. Mối liên quan giữa phân độ Sugaya với một số yếu tố lâm sàng và MRI

\begin{tabular}{|c|c|c|c|c|c|c|}
\hline \multirow[t]{2}{*}{ Các biến } & $\begin{array}{c}\text { Sugaya } 1 \\
(n=24)\end{array}$ & $\begin{array}{c}\text { Sugaya } 2 \\
(n=12)\end{array}$ & $\begin{array}{c}\text { Sugaya } 3 \\
(n=11)\end{array}$ & $\begin{array}{c}\text { Sugaya } 4 \\
(n=1)\end{array}$ & $\begin{array}{c}\text { Sugaya5 } \\
(n=4)\end{array}$ & \multirow[t]{2}{*}{$\mathbf{p}$} \\
\hline & \multicolumn{3}{|c|}{ Liền gân (n = 47) } & \multicolumn{2}{|c|}{ Rách tái phát $(n=5)$} & \\
\hline \multirow{2}{*}{ Tuổi (năm) } & $60,13 \pm 9,64$ & $59,83 \pm 5,84$ & $60,73 \pm 10,13$ & 66 & $59,75 \pm 3,3$ & 0,971 \\
\hline & \multicolumn{3}{|c|}{$60,19 \pm 8,78$} & \multicolumn{2}{|c|}{$61,00 \pm 4,00$} & 0,840 \\
\hline \multirow{2}{*}{$\begin{array}{l}\text { Giới, nam } \\
(\%)\end{array}$} & $11(45,8)$ & $5(41,7)$ & $5(45,5)$ & $0(0)$ & $2(50)$ & 0,923 \\
\hline & \multicolumn{3}{|c|}{$21 / 47(44,7)$} & \multicolumn{2}{|c|}{$2 / 5(40)$} & 0,612 \\
\hline \multirow{2}{*}{$\begin{array}{l}\text { Thoái hóa } \\
\text { mỡ (độ) }\end{array}$} & $0,79 \pm 0,42$ & $0,92 \pm 0,52$ & $1,18 \pm 0,75$ & 2 & $2,25 \pm 0,5$ & $<0,001$ \\
\hline & \multicolumn{3}{|c|}{$0,91 \pm 0,55$} & \multicolumn{2}{|c|}{$2,2 \pm 0,45$} & $<0,001$ \\
\hline \multirow{2}{*}{$\begin{array}{l}\text { Teo cơ } \\
\text { (độ) }\end{array}$} & $0,08 \pm 0,28$ & 0 & $0,72 \pm 0,65$ & 0 & $1,25 \pm 0,5$ & $<0,001$ \\
\hline & \multicolumn{3}{|c|}{$0,31 \pm 0,46$} & \multicolumn{2}{|c|}{$1 \pm 0,71$} & 0,001 \\
\hline \multirow{2}{*}{$\begin{array}{l}\text { ASES sau } \\
\text { PT }\end{array}$} & $97,67 \pm 2,58$ & $97,75 \pm 1,71$ & $93,09 \pm 5,11$ & 82 & $90 \pm 8,87$ & $<0,001$ \\
\hline & \multicolumn{3}{|c|}{$96,74 \pm 3,44$} & \multicolumn{2}{|c|}{$87,2 \pm 8,01$} & $<0,001$ \\
\hline \multirow{2}{*}{$\begin{array}{l}\text { UCLA sau } \\
\text { PT }\end{array}$} & $33,71 \pm 1,23$ & $33,58 \pm 1,38$ & $31,91 \pm 1,7$ & 29 & $30,24 \pm 2,75$ & $<0,001$ \\
\hline & \multicolumn{3}{|c|}{$33,19 \pm 1,66$} & \multicolumn{2}{|c|}{$30 \pm 2,45$} & 0,003 \\
\hline
\end{tabular}

Trong 52 bệnh nhân, nhóm có độ dày gân và tín hiệu gân bình thường (Sugaya 1) chiếm chủ yếu 24/52 bệnh nhân $(46,15 \%)$, nhóm rách tái phát bán phần chỉ có $1 / 52$ bệnh nhân $(1,92 \%)$, rách tái phát toàn phần có $4 / 52$ bệnh nhân $(7,69 \%)$.

Về thoái hóa mõ cơ trên gai, không có bệnh nhân nào rách tái phát trong 44 bệnh nhân không thoái hóa mỡ cơ và thoái hóa độ 1 . Tỷ lệ rách tái phát là $5 / 8(62,5 \%)$ bệnh nhân thoái hóa mỡ độ 2 và độ 3 (Biểu đồ 1). Có sự khác biệt về mức độ thoái hóa mỡ và teo cơ giữa các nhóm phân độ 
Sugaya với nhau và giữa 2 nhóm liền gân và rách lại sau phẫu thuật với $p<0,01$ (Bảng 1). Giữa các nhóm thoái hóa mỡ cơ thì sự khác biệt về điểm lâm sàng theo UCLA, ASES có ý nghĩa thống kê với $p<0,001$ (Bảng 2). Giữa các nhóm teo cơ có sự khác biệt về điểm lâm sàng theo UCLA, ASES có ý nghĩa thống kê với $\mathrm{p}<0,05$ (Bảng 3).



- Liền gân घRách tái phát

Biểu đồ 1. Mối liên hệ giữa thoái hóa mỡ cơ trên gai với rách tái phát sau phẫu thuật

Bảng 2. Mối liên quan giữa thoái hóa mõ và điểm lâm sàng

\begin{tabular}{|c|c|c|c|c|c|c|}
\hline Thoái hóa mõ̃ & $\begin{array}{c}\text { Độ } 0 \\
(n=8)\end{array}$ & $\begin{array}{c}\text { Độ } 1 \\
\text { (n = 36) }\end{array}$ & $\begin{array}{c}\text { Độ } 2 \\
\text { (n= 6) }\end{array}$ & $\begin{array}{c}\text { Độ } 3 \\
\text { (n = 2) }\end{array}$ & $\begin{array}{c}\text { Độ } 4 \\
(n=0)\end{array}$ & $\mathbf{p}$ \\
\hline UCLA & $33,63 \pm 1,60$ & $33,22 \pm 1,61$ & $32 \pm 1,55$ & $28 \pm 1,41$ & 0 & 0,005 \\
\hline ASES & $98,25 \pm 1,98$ & $96,75 \pm 3,42$ & $90,67 \pm 6,02$ & $85 \pm 1,31$ & 0 & $<0,001$ \\
\hline
\end{tabular}

Bảng 3. Mối liên quan giữa teo cơ và điểm lâm sàng

\begin{tabular}{lccccc}
\hline \multicolumn{1}{c}{ Teo co' } & Độ $\mathbf{0}(\mathbf{n}=\mathbf{3 9})$ & Độ $\mathbf{1}(\mathbf{n}=\mathbf{1 1})$ & Độ $\mathbf{2}(\mathbf{n}=\mathbf{2})$ & Độ $\mathbf{3}(\mathbf{n}=\mathbf{0})$ & $\mathbf{p}$ \\
\hline UCLA & $33,38 \pm 1,54$ & $31,55 \pm 2,07$ & $32 \pm 4,24$ & 0 & 0,011 \\
\hline ASES & $96,87 \pm 3,83$ & $92,56 \pm 6,34$ & $93,5 \pm 9,19$ & 0 & 0,024 \\
\hline
\end{tabular}

\section{BÀN LUẦN}

Biến chứng sau phẫu thuật rách chóp xoay bao gồm: rách tái phát, di lệch hay vỡ/rách vật liệu phẫu thuật, teo/thoái hóa mỡ cơ, tổn thương thần kinh, teo cơ delta, viêm xương khớp ổ chảo-cánh tay, cứng khớp... Tỷ lệ biến chứng sau phẫu thuật nội soi nói chung là 10,6\%; trong đó biến chứng hay gặp nhất là rách tái phát. ${ }^{10}$
Nghiên cứu của chúng tôi chỉ ra tỷ lệ rách tái phát sau phẫu thuật là $9,62 \%$, các bệnh nhân này đều đã được phát hiện rách tái phát trong thời gian trước 6 tháng. Điều này phù hợp với các nghiên cứu trước đó về tỷ lệ rách tái phát khoảng $9-36 \%$ và thời gian hay gặp rách tái phát là trong 6 tháng đầu sau phẫu thuật, ,3,5,8 tỷ lệ rách tái phát không thay đổi giữa 6 tháng và 2 
năm đầu sau phẫu thuật. ${ }^{3}$

Kết quả lâm sàng bao gồm ASES và UCLA được cải thiện đáng kể sau phẫu thuật. ${ }^{11,12}$ Trong nghiên cứu của chúng tôi kết quả lâm sàng chủ yếu nằm trong nhóm tốt và rất tốt. Nghiên cứu của Yoo và cộng sự đã báo cáo rằng cả hai nhóm liền gân và rách tái phát sau phẫu thuật đều cho thấy kết quả lâm sàng được cải thiện, nhưng nhóm được chữa lành cho kết quả tốt hơn. ${ }^{12}$ Nhóm rách tái phát được so sánh với nhóm liền gân và cho kết quả lâm sàng kém hơn so với nhóm liền gân. Điểm ASES và UCLA trung bình trong nhóm rách tái phát lần lượt là 88,3 và 32 , trong khi những người trong nhóm liền gân lần lượt là 93,1 và 33,8 (với $p<0,001$ ). ${ }^{12}$ Tương tự, nghiên cứu của chúng tôi chỉ ra giữa hai nhóm liền gân và rách tái phát sau phẫu thuật có sự khác biệt về điểm lâm sàng tính theo thang điểm UCLA, ASES. Khi xét riêng điểm UCLA và ASES sau phẫu thuật theo các độ Sugaya thì sự khác biệt về điểm lâm sàng giữa các nhóm cũng có ý nghĩa (Hình 1A, 2A, 3A). Tuy nhiên, nghiên cứu của Malavolta lại cho kết quả không có tương quan giữa Sugaya và điểm UCLA sau phẫu thuật. ${ }^{8}$ Điều này được giải thích là nhóm nghiên cứu của Malavolta phân chia Sugaya thành 3 nhóm: Sugaya 1, Sugaya 2 và Sugaya $\geq 3,{ }^{8}$ nghiên cứu của chúng tôi chia cụ thể Sugaya thành 5 nhóm. Ngoài ra, Sugaya độ 3 chưa được coi rách tái phát, điểm lâm sàng của Sugaya độ 3 cao hơn so với độ 4 và độ $5,{ }^{13}$ vì thế khi chúng tôi xét điểm UCLA và ASES theo 2 nhóm liền gân (Sugaya 1,2,3) và rách tái phát (Sugaya 4,5 ) thì có thể thấy sự khác biệt.

Việc đánh giá hai dấu hiệu thoái hóa mỡ cơ và teo cơ là một phần quan trọng trong việc đánh giá sau phẫu thuật. Lưu ý rằng teo cơ và thoái hóa mỡ thường không thể hồi phục sau khi phẫu thuật tuy nhiên có liên quan đến sự thành công của phẫu thuật, được chứng minh là một yếu tố tiên lượng xấu đối với phẫu thuật chóp xoay. Hiện nay với MRI và cắt lớp vi tính, sự hiện diện của teo cơ và thâm nhiễm mỡ cơ có thể được đánh giá một cách đáng tin cậy. ${ }^{4,14}$ Nghiên cứu của chúng tôi cho thấy không gặp rách tái phát ở các bệnh nhân không thoái hóa mỡ cơ và thoái hóa độ 1 , mà gặp ở các bệnh nhân thoái hóa mỡ độ 2 và độ 3 . Giữa các nhóm phân độ Sugaya với nhau và giữa 2 nhóm liền gân và rách lại sau phẫu thuật đều có khác biệt về mức độ thoái hóa mỡ và teo cơ', ngoài ra, chỉ số thoái hóa mỡ tương quan nghịch với điểm lâm sàng (Hình 1B, 2B, 3B). Theo Goutallier và cộng sự, tỷ lệ thoái hóa mỡ cao có tương quan với kết quả phẫu thuật không đạt yêu cầu và tỷ lệ rách tái phát cao. ${ }^{15}$ Nghiên cứu của Choi trên 147 bệnh nhân cho kết quả tương tự, tỷ lệ rách tái phát và thoái hóa mỡ cũng có mối tương quan, hơn nữa, tỷ lệ rách tái phát được tìm thấy ở $18(35,3 \%)$ trong số 51 trường hợp thoái hóa mỡ độ 3 và độ $4 .{ }^{4} \mathrm{Hạn}$ chế nghiên cứu của chúng tôi là không có MRI trước phẫu thuật, nên chỉ ghi nhận đồng thời mức độ thoái hóa mỡ - teo cơ tại thời điểm sau phẫu thuật với tỷ lệ rách tái phát và tình trạng lâm sàng khớp vai.

Nghiên cứu này cũng có những hạn chế khác cần được nhắc đến là chất lượng hình ảnh có thể bị nhiễu bởi vật liệu phẫu thuật gây đánh giá sai phân độ, tuy nhiên ngày nay, hầu hết các vật liệu sử dụng trong phẫu thuật chỉnh hình đều làm từ titanium là hợp kim kim loại thuận từ, và do đó gây ra nhiễu ảnh ít nghiêm trọng hơn đáng kể so với các chất sắt từ như trước kia. Ngoài ra, do tình hình dịch bệnh Covid-19 diễn ra phức tạp trong năm 2020 - 2021 nên số lượng bệnh nhân còn ít so với các nghiên cứu khác và phim chụp MRI khớp vai không thực hiện ở cùng một cơ sở, dẫn tới có ít nhiều sự khác biệt về các chuỗi xung cũng như kỹ thuật khử nhiễu. Các suy luận chung về các hạn chế của thuật toán cần được xác nhận trong các nghiên cứu lớn hơn. 

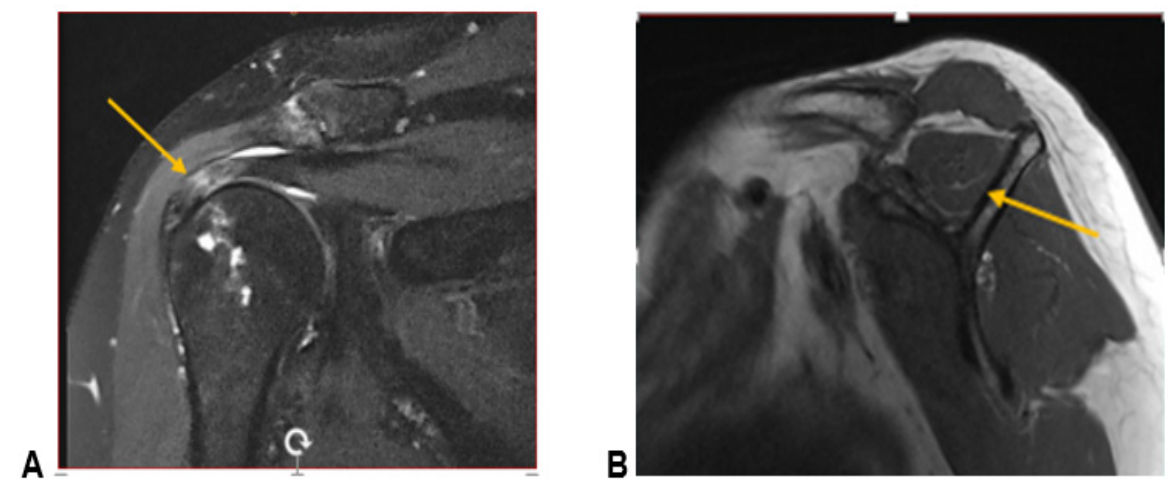

Hình 1. Nữ 59 tuổi, khám lại sau 12 tháng phẫu thuật gân trên gai bên phải. CHT PD FS đứng ngang $(\mathrm{A})$ : chiều dày của gân đồng đều, tín hiệu gân tăng nhẹ, không có đường rách gân, Sugaya độ 2 (mũi tên). T1W đứng dọc (B): cơ trên gai không teo, chỉ số thoái hóa mõ độ 1 (mũi tên). Lâm sàng cải thiện rất tốt sau phẫu thuật với điểm $A S E S=100, U C L A=35$
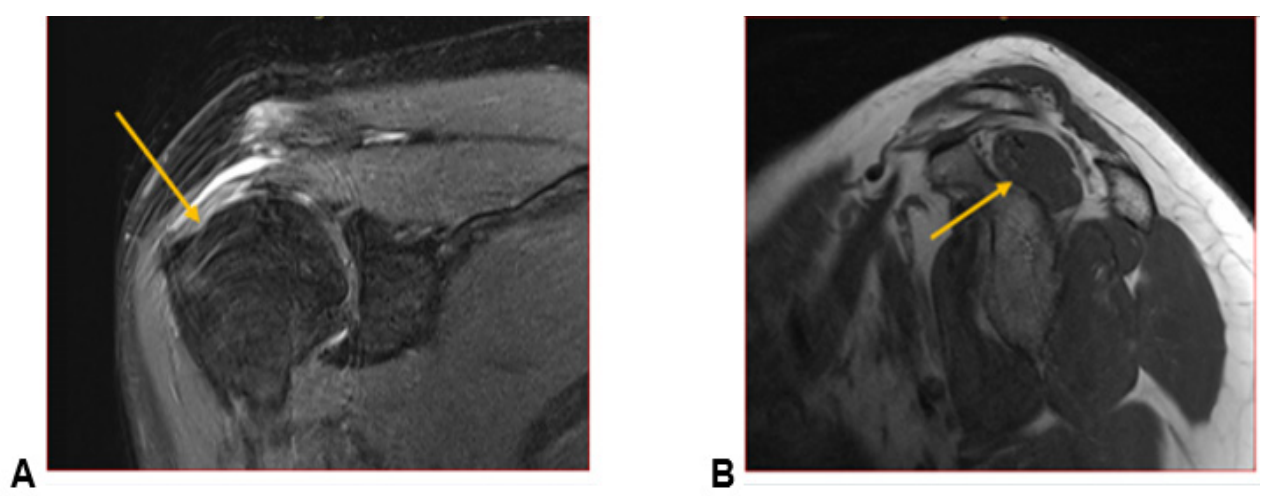

Hình 2. Nữ 68 tuổi, khám lại sau 12 tháng phẫu thuật gân trên gai bên phải. CHT PD FS đứng ngang $(A)$ : độ dày gân mỏng, tín hiệu gân không đồng nhất, không thấy đường rách gân, Sugaya độ 3 (mũi tên). T1W đứng dọc (B): cơ trên gai không teo, chỉ số thoái hóa mõ độ 1 (mũi tên). Lâm sàng cải thiện rất tốt sau phẫu thuật với điểm ASES $=97, \mathrm{UCLA}=32$

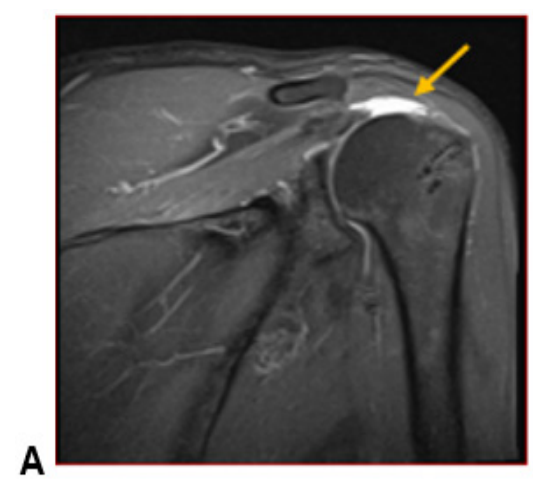

B

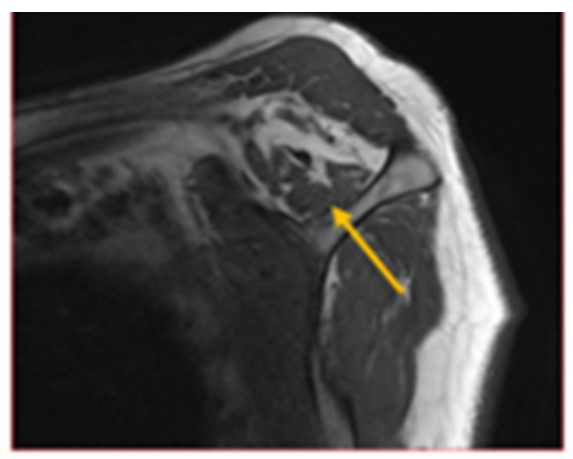

Hình 3. Nam 62 tuổi, khám lại sau 6 tháng phẫu thuật gân trên gai bên trái. CHT PD FS đứng ngang (A): rách toàn bộ gân trên gai, Sugaya độ 5 (mũi tên). T1W đứng dọc (B): cơ trên gai teo, chỉ số thoái hóa mõ̃ độ 2 (mũi tên). Lâm sàng cải thiện sau phẫu thuật với điểm ASES= 87, UCLA= 29 


\section{KẾT LUẬN}

Sau phẫu thuật rách chóp xoay, đa số bệnh nhân có tình trạng khớp vai ở mức tốt và rất tốt. Chụp MRI sau phẫu thuật cho thấy các bệnh nhân có phân độ Sugaya thấp hơn thì tình trạng khớp vai sau phẫu thuật tốt hơn. Nghiên cứu cũng nghi nhận các bệnh nhân có chỉ số thoái hóa mõ' cao và có teo cơ trên MRI có tình trạng khớp vai kém hơn và có nguy cơ rách tái phát cao hơn. Với các bệnh nhân có phân độ Sugaya cao sau phẫu thuật thì cần tập phục hồi chức năng tốt để đảm bảo khả năng bù trừ chức năng cơ Delta thay thế cho chức năng cơ chóp xoay.

\section{Lò̀i cảm ơn}

Chúng tôi xin chân thành cảm ơn các đồng nghiệp khoa Chẩn đoán hình ảnh của Bệnh viện Đa khoa Xanh Pôn Hà nội và của Bệnh viện Đại học $Y$ Hà nội đã giúp đỡ chúng tôi hoàn thành nghiên cứu này.

\section{TÀI LIẸU THAM KHẢO}

1. Minagawa $\mathrm{H}$, Yamamoto $\mathrm{N}$, Abe $\mathrm{H}$, et al. Prevalence of symptomatic and asymptomatic rotator cuff tears in the general population: From mass-screening in one village. J Orthop. 2013; 10(1): 8-12. doi:10.1016/j.jor.2013.01.008

2. Neviaser RJ. Evaluation and management of failed rotator cuff repairs. Orthop Clin North Am. 1997; 28(2): 215-224. doi:10.1016/s00305898(05)70281-9

3. Le BTN, Wu XL, Lam PH, Murrell GAC. Factors predicting rotator cuff retears: an analysis of 1000 consecutive rotator cuff repairs. Am J Sports Med. 2014; 42(5): 11341142. doi:10.1177/0363546514525336

4. Choi S, Kim MK, Kim GM, Roh Y-H, Hwang IK, Kang H. Factors associated with clinical and structural outcomes after arthroscopic rotator cuff repair with a suture bridge technique in medium, large, and massive tears. J Shoulder Elbow Surg. 2014; 23(11): 1675-1681. doi:10.1016/j.jse.2014.02.021

5. Diebold G, Lam P, Walton J, Murrell GAC. Relationship Between Age and Rotator Cuff Retear: A Study of 1,600 Consecutive Rotator Cuff Repairs. J Bone Jt Surg. 2017; 99(14): 1198-1205. doi:10.2106/JBJS. 16.00770

6. Koh KH, Laddha MS, Lim TK, Park $\mathrm{JH}$, Yoo JC. Serial structural and functional assessments of rotator cuff repairs: do they differ at 6 and 19 months postoperatively? J Shoulder Elbow Surg. 2012; 21(7): 859-866. doi:10.1016/j.jse.2011.05.027

7. Collin P, Yoshida M, Delarue A, Lucas C, Jossaume T, Lädermann A. Evaluating postoperative rotator cuff healing: Prospective comparison of MRI and ultrasound. Orthop Traumatol Surg Res. 2015; 101(6): S265-S268. doi:10.1016/j.otsr.2015.06.006

8. Malavolta EA, Assunção JH, Ramos FF, et al. Serial structural MRI evaluation of arthroscopy rotator cuff repair: does Sugaya's classification correlate with the postoperative clinical outcomes? Arch Orthop Trauma Surg. 2016; 136(6): 791797. doi:10.1007/s00402-016-2429-5

9. Phan Đình Mừng, Trần Đình Chiến, Phạm Đăng Ninh. Kết quả chụp cộng hưởng từ sau phẫu thuật nôi soi khâu chóp xoay rách: tương quan giữa chỉ số thoái hóa mỡ với phục hồi chức năng khớp vai. Tạp chí Y học Việt Nam. 2018; 7(2): 13-16.

10. Beltran LS, Bencardino JT, Steinbach LS. Postoperative MRI of the shoulder. J Magn Reson Imaging JMRI. 2014; 40(6): 1280-1297. doi:10.1002/jmri.24570

11. Gladstone JN, Bishop JY, Lo IKY, Flatow EL. Fatty infiltration and atrophy of the rotator cuff do not improve after rotator cuff repair and correlate with poor functional outcome. Am J Sports Med. 2007; 35(5): 719-728. 
doi:10.1177/0363546506297539

12. Yoo JH, Cho NS, Rhee YG. Effect of postoperative repair integrity on health-related quality of lifeafter rotatorcuffrepair: healed versus retear group. Am J Sports Med. 2013; 41(11): 2637-2644. doi:10.1177/0363546513499152

13. Muniandy M, Niglis L, Dosch JC, Meyer N, Kempf JF, Collin P. Postoperative rotator cuff integrity: can we consider type 3 Sugaya classification as retear? J Shoulder Elbow Surg. 2021; 30(1): 97-103. doi:10.1016/j. jse.2020.05.002
14. Thakkar RS, Thakkar SC, Srikumaran $U$, McFarland EG, Fayad LM. Complications of rotator cuff surgery - the role of post-operative imaging in patient care. $\mathrm{Br} J$ Radiol. 2014; 87(1039): 20130630. doi:10.1259/bjr.20130630

15. Goutallier D, Postel J-M, Gleyze P, Leguilloux $P$, Van Driessche $S$. Influence of cuff muscle fatty degeneration on anatomic and functional outcomes after simple suture of full-thickness tears. J Shoulder Elbow Surg. 2003; 12(6): 550-554. doi:10.1016/S10582746(03)00211-8

\section{Summary \\ CORRELATION BETWEEN MRI FINDINGS AND CLINICAL OUTCOME AFTER ROTATOR CUFF REPAIR}

The purpose of this study was to investigate the relationship between postoperative MRI images and clinical outcome on 52 patients after arthroscopic rotator cuff repair at least 6 months, from January 2020 to June 2021 . The results showed that the rate of recurrent supraspinatus muscle tendon tear was $9.62 \%$ and all patients were found to have recurrent tear within 6 months after surgery. The clinical improvement after surgery was significant, most of them were at good and excellent levels. There was a concordance between the Sugaya classification on MRI features with clinical score according to UCLA, ASES with $p<0.001$. The relationship between fatty degeneration and muscle atrophy with clinical score and rate of recurrent tear was significant with $p<0.05$. Thus, patients with lower Sugaya grades have better shoulder joint conditions after surgery. Patients with a high index of fatty degeneration and muscle atrophy on MRI have poorer clinical outcome and a higher risk of recurrent tearing.

Keywords: After rotator cuff repair, recurrent tears, rotator cuff MRI, Sugaya, UCLA, ASES. 